\title{
Cardiac complications during the active phase of COVID-19: review of the current evidence
}

\author{
Mohammad Said Ramadan ${ }^{1}$ [ - Lorenzo Bertolino ${ }^{1}$ (i) - Tommaso Marrazzo ${ }^{1} \cdot$ Maria Teresa Florio $^{1}$. \\ Emanuele Durante-Mangoni ${ }^{1}$ (1) on behalf of The Monaldi Hospital Cardiovascular Infection Study Group
}

Received: 9 March 2021 / Accepted: 12 May 2021 / Published online: 27 May 2021

(c) The Author(s) 2021

\begin{abstract}
Growing reports since the beginning of the pandemic and till date describe increased rates of cardiac complications (CC) in the active phase of coronavirus disease 2019 (COVID-19). CC commonly observed include myocarditis/myocardial injury, arrhythmias and heart failure, with an incidence reaching about a quarter of hospitalized patients in some reports. The increased incidence of $\mathrm{CC}$ raise questions about the possible heightened susceptibility of patients with cardiac disease to develop severe COVID-19, and whether the virus itself is involved in the pathogenesis of CC. The wide array of CC seems to stem from multiple mechanisms, including the ability of the virus to directly enter cardiomyocytes, and to indirectly damage the heart through systemic hyperinflammatory and hypercoagulable states, endothelial injury of the coronary arteries and hypoxemia. The induced CC seem to dramatically impact the prognosis of COVID-19, with some studies suggesting over 50\% mortality rates with myocardial damage, up from $\sim 5 \%$ overall mortality of COVID-19 alone. Thus, it is particularly important to investigate the relation between COVID-19 and heart disease, given the major effect on morbidity and mortality, aiming at early detection and improving patient care and outcomes. In this article, we review the growing body of published data on the topic to provide the reader with a comprehensive and robust description of the available evidence and its implication for clinical practice.
\end{abstract}

Keywords COVID-19 · Cardiac complications $\cdot$ SARS-CoV-2 $\cdot$ Pathophysiology $\cdot$ Heart disease

\section{Introduction}

Severe acute respiratory syndrome coronavirus 2 (SARS$\mathrm{CoV}-2)$ is a novel beta-coronavirus responsible for the ongoing coronavirus disease 2019 (COVID-19) pandemic, whose real prevalence is thought to be largely higher than reported [1]. Primarily categorized as a respiratory virus, SARSCoV-2 has also been implicated in a number of extrapulmonary manifestations, including but not limited to renal, neurological and cardiovascular disorders [2]. The relationship

The members of the Monaldi Hospital Cardiovascular Infection Study Group are listed in Acknowledgements.

Emanuele Durante-Mangoni

emanuele.durante@unicampania.it

1 Department of Precision Medicine, University of Campania 'L. Vanvitelli' and Unit of Infectious and Transplant Medicine, AORN Ospedali Dei Colli-Monaldi Hospital, Piazzale E. Ruggieri, 80131 Napoli, Italy between COVID-19 and the cardiovascular system seems quite complex and to-date not completely understood [3].

Full genomic and phylogenetic analysis of SARS-CoV-2 showed it to closely resemble severe acute respiratory syndrome coronavirus (SARS-CoV) (79\%), the virus responsible for the first pandemic in the twenty-first century, and distantly the Middle East respiratory syndrome coronavirus (MERS-CoV) (50\%), which has caused recurrent outbreaks, most recently on March 17th, 2021 in the United Arab Emirates $[4,5]$. The latter viruses are thought to interact with the cardiovascular system, as cardiac diseases (CD) were highly prevalent among infected patients- indicating increased susceptibility of this subgroup, and CD associated with worse outcomes [6, 7].

Alarmingly, CC such as myocardial injury/myocarditis, arrhythmias and heart failure are also increasingly reported in patients with COVID-19, suggesting that COVID-19 could promote $\mathrm{CC}[8,9]$. Multiple pathophysiological mechanisms have been reported for the latter observation, including systemic cytokine storm, direct myocardial damage, and 
hypercoagulable state, which are suggested to be induced by SARS-CoV-2 infection [3]. Moreover, there seems to be reciprocated prognostic worsening of both diseases. Despite having low case fatality rates of $<5 \%$ in most countries [11], COVID-19 mortality soared in patients with myocardial damage, with some reaching 50\% [11]. A recent systematic review and meta-analysis, with more than 20,000 COVID19 patients, concluded 3 and 11 times higher risk, for both intensive care unit (ICU) admission and ICU mortality, with CD history and acute cardiac injury, respectively, compared to patients with no prior history of CD [12].

Considering these data, there is a stringent need for the Clinician to understand incidence, risk factors, mode of presentation, diagnostic strategies and prognosis of cardiac involvement in COVID-19 and learn how to best prevent or treat it, based on the existing evidence.

In this review, we aim to summarize the available studies investigating cardiac manifestations in adult patients focusing on the acute phase of COVID-19, to increase the understanding of the mutual COVID-heart relationship and highlight the corresponding clinical implications on practice, surveillance programs and guidelines. At variance with previous reports, we exploit in a greater detail the growing body of published data to provide the reader with a comprehensive and robust description of the available evidence and eventually highlight the clinical implications of described data.

\section{Pathophysiology}

Until our present day, the exact mechanisms of cardiac injury by COVID-19 are not completely understood [3]. The major suggested pathophysiological links between both diseases are described in Fig. 1. One postulated mechanism stems from confirming that SARS-CoV-2, like SARS-CoV, uses its spike (S) protein to attach to the angiotensin-converting enzyme 2 (ACE2) receptor, found on the surface of host cells, and highly expressed in the heart, kidneys, lungs and blood vessels [13]. ACE2 is also part of the renin-angiotensin-aldosterone system (RAAS), whose final product and main effector is Angiotensin-II (Ang-II), a molecule that widely participates in cardiovascular disease (CVD) such as hypertension, MI and heart failure [14]. When Ang-II binds to angiotensin type-1 receptor, it causes vasoconstriction, inflammatory responses, increased blood coagulation, and extracellular matrix remodeling, which explains its strong association with CVD [14]. ACE2 can transform Ang-II into angiotensin-(1-7), which mediates the opposite effects of Ang-II, including vasodilation (also in coronary arteries), decreased proliferation and inflammation and vascular protection [14]. That is why, long before COVID-19, ACE2 was shown to be involved in the pathogenesis of a number of diseases, like diabetes mellitus, heart failure and hypertension, and to play a protective role in the heart and lungs $[3,13]$. In patients with SARS-CoV, several studies showed downregulation of ACE2 in the heart and lungs, and reasoned that the same mechanism could explain cardiac injury with COVID-19, as both viruses bind to ACE2 [15]. Albeit the expanding evidence, high ACE2 receptor expression does not necessarily translate into more infection rates nor ACE2 downregulation to cardiac injury [3].

Another suggested mechanism is indirect cardiac injury by stimulating a systemic and dysfunctional immune response, manifesting as a cytokine storm [16]. This was especially seen with severe COVID-19, and displayed as high plasma levels of inflammatory cytokines such as IL-2, IL-7, IL-10, and tumor necrosis factor (TNF) [17]. The increased cytokines in turn mediate local injury to the lung, resulting in diffuse alveolar damage such as hyaline membrane formation and pulmonary edema [18], and can mediate multi-organ failure and myocardial damage. Moreover, bronchoalveolar lavage from patients with severe disease showed increased levels of proinflammatory monocytederived macrophages [19]. These activated macrophages secrete a number of molecules, including collagenases, which degrade collagen-a major constituent of fibrous caps-and can lead to plaque rupture, possibly inducing acute coronary syndromes (ACS) [20].

A prothrombotic state was also described in COVID-19, with pulmonary embolism, venous thromboembolism, and disseminated intravascular coagulation (DIC) commonly observed as complications in critically ill patients [3]. In one COVID-19 autopsy series, platelet and megakaryocyterich thrombi were found in multiple organs including the heart, kidney and lungs, in some cases despite full anticoagulation [21]. This can result from increased tissue factor, a potent procoagulant from activated macrophages, increased fibrinogen and factor VIII levels and/or from direct endothelial damage that could be caused by SARS-CoV-2 infection [22]. Indeed, in a series of post mortem analysis of COVID19 patients, SARS-CoV-2 was shown to directly mediate endothelial damage across a number of vascular beds [23]. As endothelial cells are central components to all organs and highly express ACE2, endothelial inflammation induced by SARS-CoV-2 could explain the multiorgan damage in general, and cardiac injury specifically [3].

\section{Cardiovascular disease and COVID-19}

Growing studies highlight the peaking prevalence of comorbid conditions in COVID-19, especially in critical cases [24-26]. Common reported comorbidities included mostly hypertension, followed by diabetes and coronary heart disease $[17,27]$. Poor outcomes were associated with these 
Fig. 1 Major pathophysiological pathways linking COVID-19 to heart disease. Ang-II Angiontensin-II, ACE2 angiotensin-converting enzyme 2, $I L$ interleukin, $T F$ tissue factor, $T N F$ tumour necrosis factor. Sources: Sarscov2: "Coronavirus" by Yu. Samoilov is licensed under CC BY 2.0, https://www.flickr.com/photos/ yusamoilov/49678500083/ in/photostream/. Endothelial Injury: Normal vs. PartiallyBlocked Vessel by BruceBlaus, https://commons.wikimedia. org/wiki/File:Blausen_0052_ Artery_NormalvPartially-Block edVessel.png. Inflammation: "Fig. 1 from 'Sex Differences in Inflammation During Atherosclerosis'" by Libertas Academica is licensed under CC BY 2.0, https://search.creativeco mmons.org/photos/7991b0ee963d-42bc-bc85-fa2f19396d a8. Hypoxia: Exercise/Contraction/Hypoxia, Indolences, https://commons. wikimedia. org/wiki/File:Muscle_pathw ays.svg. Viral attachment: The coronavirus replication cycle, Crenim at English Wikipedia, edited. https://commons.wikim edia.org/wiki/File:Coronavirus_ replication.png

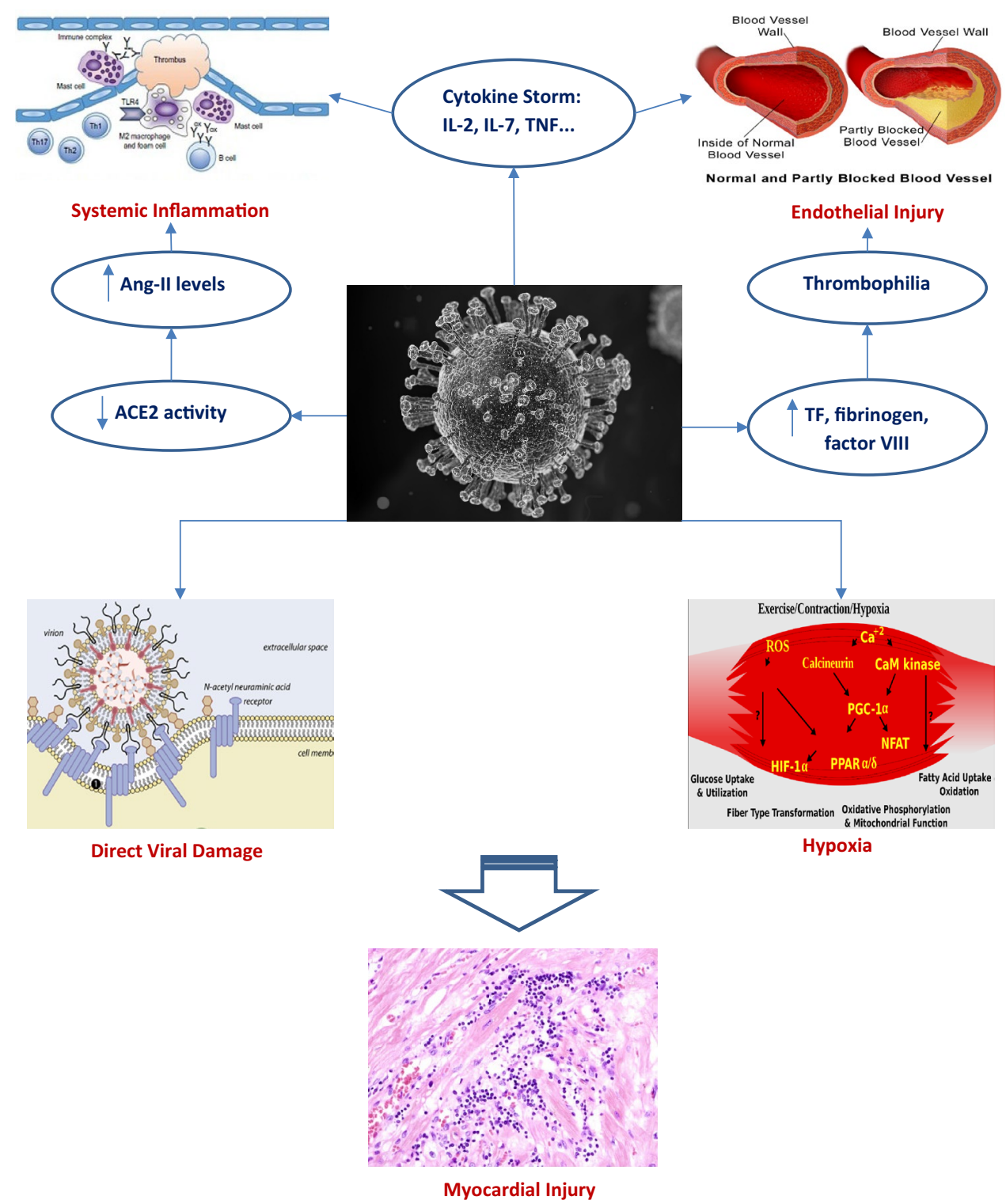

with severe COVID-19 [29]. Hypertension associates with increased RAAS activation, an imbalance between Ang-II and angiotensin-(1-7), and is a major risk for mortality in CVDall of which could heighten the risk for a severe COVID-19 [30]. Furthermore, immune senescence in the elderly is associated with a low-grade pro-inflammatory state and immune dysfunction, which could delay viral clearance and induce an unregulated inflammatory response and cytokine release, worsening organ damage and delaying recovery [31] (Fig. 2). 


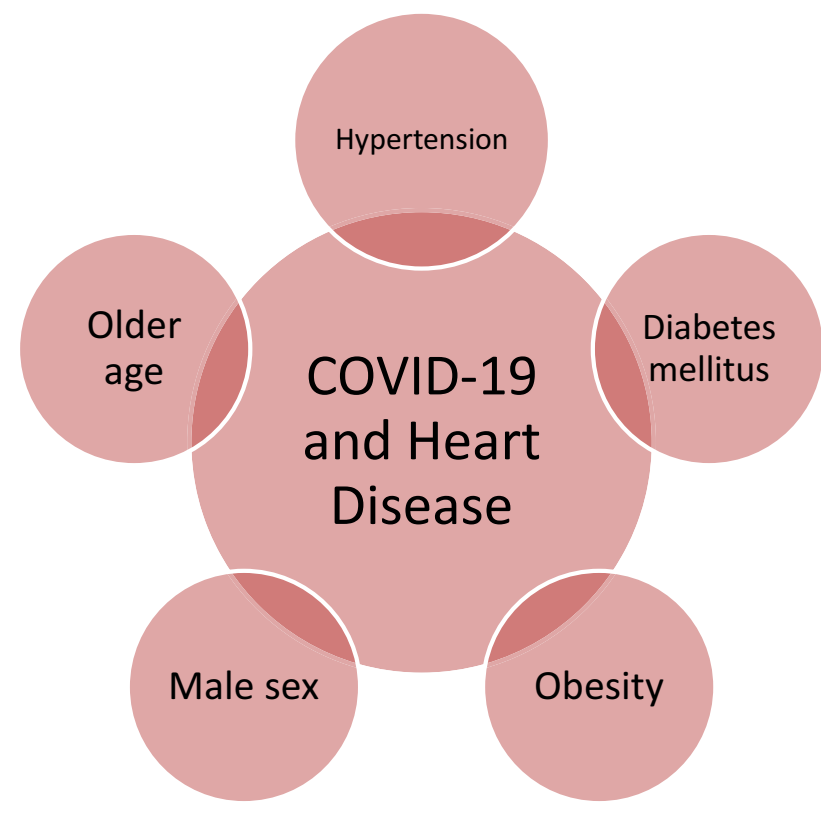

Fig. 2 Commonly reported risk factors associated with both heart disease and severe COVID-19

\section{Cardiac complications during acute COVID-19}

Although major COVID-19 complications relate to the respiratory system [12], a wide range of cardiac diseases were proposed to be caused by the disease [8,32-36], and could be the presenting symptoms of COVID-19, even without the typical respiratory symptoms [35, 37]. The most important cardiac complications that have been described and can be observed during the acute phase of COVID-19 are summarized in a pictorial view in Fig. 3.

\section{Myocardial injury/Myocarditis}

Myocardial injury has been described since early COVID19 reports from China, where up to $17 \%$ of inpatients had elevated troponin, and associated with higher ICU admission $(31 \%$ vs $4 \%)$ and mortality ( $46 \%$ vs $1 \%)[17,38]$. More recently, a meta-analysis with 26 studies and 11,685 patients found that myocardial injury, assessed mostly by elevated troponin and/or creatinine kinase MB, is present in about $20 \%$ of hospitalized patients (range 5-68\%) [39]. Despite the increasing reports, pathophysiological mechanisms linking myocardial injury with COVID-19 are still evolving. Some proposed mechanisms include increased systemic inflammation and cytokine storm, respiratory failure and hypoxemia, hypercoagulability leading to increased coronary thrombosis, and direct cardiomyocyte damage through viral attachment [3].
The diagnosis of myocarditis, in general, is one of the most challenging cardiac diagnoses, owing to its wide range of clinical presentations [40]. It can be diagnosed clinically or histologically by endomyocardial biopsy (EMB), the latter being the gold standard, although not commonly performed. The 2013 European Society of Cardiology position statement defines clinically suspected myocarditis in a patient having $\geq 1$ clinical criterion such as chest pain or palpitations and $\geq 1$ diagnostic criterion such as elevated troponin I or $\mathrm{T}$, electrocardiography (ECG) or cardiac magnetic resonance (CMR) findings [40]. Comparing that with the reported cases of myocarditis in COVID-19 patients, most presented with fever (up to 58\%), dyspnea (up to $74 \%$ ), and chest pain (up to $25 \%$ ) [41, 42], which coincide with the previous diagnostic symptoms of myocarditis [40]. Moreover, utilized diagnostic methods included cardiac biomarkers levels, ECG, echocardiography, and CMR, showed a wide range of abnormalities reaching up to $90,84,79$, and $76 \%$, respectively [41, 42], which could further support myocardial injury. CMR changes included late gadolinium enhancement $(50 \%)$ and diffuse edema and myocardial inflammation (76\%); alarmingly, the former could be associated with lifethreatening arrythmias and sudden cardiac death [43], and the latter with severe complications including heart failure [44]. Histologic evidence is still limited, EMB, done in a minority of the patients, demonstrated myocardial inflammation with predominant macrophages, confirming myocardial inflammation (eight cases), and one case showed SARS$\mathrm{CoV}-2$ in cardiomyocytes [41], providing in-vivo proof of possible direct viral injury (Table 1).

Myocardial injury and myocarditis do not only seem to associate with COVID-19, but to also worsen its prognosis. In an early study from Wuhan, China, with 187 patients, mortality rate increased from 7.62 to $13.3 \%$ in those with CVD history, and to $37.5 \%$ with both CVD history and acutely increased troponin $\mathrm{T}$ [8]. These early observations were also supported by more recent systematic reviews of myocarditis cases, where mortality rates with myocarditis were higher than the reported overall COVID-19 mortality [11], and ranged from 13 to $26 \%$ [41, 42, 45]. In addition to increasing mortality, myocardial injury could worsen COVID-19 recovery course. In one study, those with cardiac injury (defined as elevated troponin $>99$ th percentile) were more likely to require mechanical ventilation (noninvasive: $46.3 \%$ vs $3.9 \%$; invasive: $22 \%$ vs $4.2 \%$ ), had more multi-system complications, such as acute respiratory distress syndrome ( $58.5 \%$ vs $14.7 \%$ ), in addition to higher mortality (51.2\% vs $4.5 \%)$ [9]. This was also observed in a recent systematic review of cases with myocarditis, where although $\sim 80 \%$ of inpatients with myocarditis survived, $50 \%$ (7/14) needed vasopressors during their hospitalization, 25\% (4/14) required inotropic support, and 14\% (2/14) required extracorporeal membrane oxygenation [45]. 

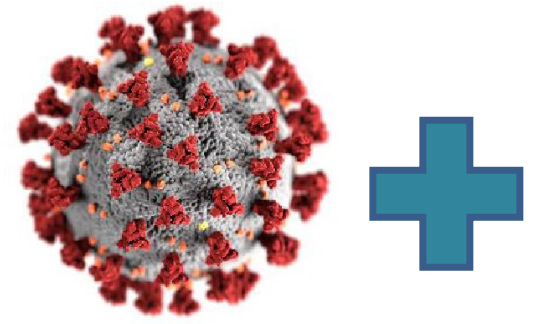

SARS-COV-2

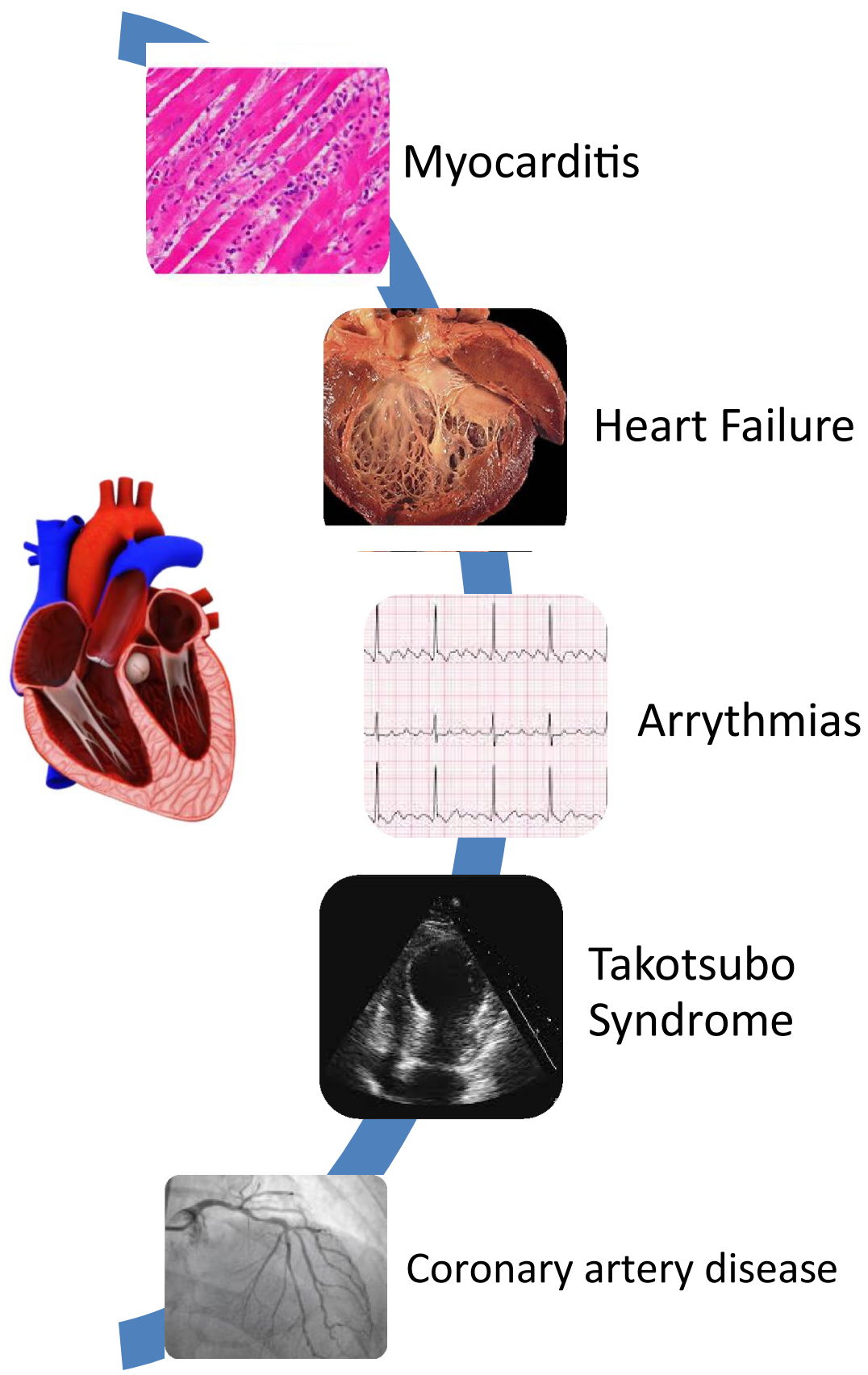

Fig. 3 Common cardiac complications associated with COVID-19

Myocarditis resulting from other viruses, such as Influenza and Epstein-Barr Virus, associated with long-term complications, including heart failure, impaired exercise tolerance, arrythmias and sudden cardiac death [46]. In COVID-19, few studies followed up patients after acute cardiac injury. In a single center pilot study, 48 in-patients were followed up by echocardiography 6 months post-discharge [47]. Results showed that as compared to patients without cardiac injury during hospitalization, those with cardiac injury during the acute COVID-19 phase were more likely to have significant diastolic dysfunction induced by low level exercise [47]. As subclinical myocarditis may carry a high risk for sudden cardiac death during moderate-high intensity physical activity [48, 49], further studies on this specific topic are urgently needed.

Despite suggesting a possible relationship between myocarditis and COVID-19, interpretation of these studies requires caution, as the available evidence remains limited for many reasons [11, 15, 45, 47]. First, few of the reported cases had histologically confirmed myocarditis by 
Table 1 Common signs and symptoms and diagnostic modalities for COVID-19-associated myocardial injury and Takotsubo syndrome

\begin{tabular}{|c|c|c|c|c|c|}
\hline Diagnosis & Signs and symptoms & Echocardiography & ECG & CMR & Biomarkers \\
\hline Myocardial injury & $\begin{array}{l}\text { Dyspnea, fever, chest } \\
\text { pain }\end{array}$ & $\begin{array}{l}\text { Systolic/diastolic dys- } \\
\text { function, pericardial } \\
\text { effusion }\end{array}$ & $\begin{array}{l}\text { ST-segment elevation } \\
\text { and depression, T wave } \\
\text { changes, ventricular } \\
\text { tachycardia }\end{array}$ & $\begin{array}{l}\text { Increased T1, T2 map- } \\
\text { ping, late gadolinium } \\
\text { enhancement }\end{array}$ & Elevated \\
\hline Takotsubo syndrome & Chest pain, dyspnea & $\begin{array}{l}\text { Apical akinetic expansion } \\
\text { (apical ballooning), } \\
\text { hypokinesia hyper- } \\
\text { dynamic contractil- } \\
\text { ity, reduced ejection } \\
\text { fraction }\end{array}$ & $\begin{array}{l}\text { ST-segment elevation } \\
\text { and/or depression with } \\
\text { T-wave inversion }\end{array}$ & No data available & Elevated \\
\hline
\end{tabular}

EMB — which is still the gold standard for diagnosis; instead, most studies relied on clinical, biomarkers' levels and imaging criteria for myocardial injury diagnosis [15, 50]. Moreover, the pathophysiological mechanism for such an association is not yet defined, and hence prevention methods could be difficult to predict to reduce the incidence of myocardial injury. Lastly, studies with larger sample sizes and long follow-up could better predict and categorize SARS-CoV-2 associated cardiac injury.

Thus, larger studies with more robust diagnostic techniques and a design including control groups are needed to further assess the relationship between myocarditis and SARS-CoV-2. No further recommendations can be done on myocarditis management in COVID-19, based on existing evidence.

\section{Takotsubo syndrome}

Takotsubo syndrome (TTS) is an acute and transient myocardial contractility impairment leading to acute heart failure, in the absence of coronary artery disease [51]. Several reports described TTS [52-57], more commonly associated with concomitant severe COVID-19 [52-54, 56, 57]. TTS is most often observed in post-menopausal women $(\sim 90 \%)$ [51], which is also seen in COVID-19-associated TTS [50, 52, 54-57], however, TTS is also seen in males [33, 58], and could reach up to $33 \%$ of cases [50]. The clinical presentation of TTS could be like that of acute myocardial infarction (MI) with chest pain and/or dyspnea, ST-segment elevation and/or depression with T-wave inversion on ECG, and elevated cardiac biomarkers [51], which closely match the presentations of patients with COVID-19 associated TTS [33, 49, 52-54, 57]. Current literature shows a 4-5\% of in-hospital mortality with TTS [51], which could greatly increase with COVID-19, reaching $40 \%$ in one series [33].

In addition to possibly increasing mortality, TTS appears to also worsen COVID-19 disease course. Most reported TTS patients had cardiac or respiratory decompensations during their hospitalizations for COVID-19, ranging from increased oxygen requirement, need for vasopressors [33, 50,
52, 53, 55] and in severe cases, ECMO [53, 56]. Although it seems that most patients eventually recover and are discharged, TTS could associate with long-term cardiac and non-cardiac-related morbidity and increased total mortality [51], and so patients with COVID-19 and TTS beyond the acute phase of the disease is warranted.

To date, the exact pathophysiology of TTS is not known. However, major roles of sympathetic stimulation from sudden stress or major physical illness and myocardial inflammation have been proposed [51]. Sympathetic receptors were found to be more concentrated in the cardiac apex, suggesting the apex could be more susceptible for increased levels of catecholamines. Moreover, growing studies show that increased inflammation and particularly ongoing inflammation associates with TTS [36]. In COVID-19, a number of studies showed the pandemic to be associated with significantly increased emotional stress, including anxiety and depression [58], which could increase the risk of TTS by increasing sympathetic stimulation. Furthermore, COVID19, especially severe cases, are associated with heightened acute and ongoing inflammatory response, which could further increase TTS risk [3].

Thus, current evidence suggests the relationship between TTS and SARS-CoV-2 infection is mediated by emotional stress as well as hyper-inflammatory changes. Overall, the prognosis of TTS in COVID-19 patients seems fair in terms of cardiac functional recovery.

\section{ACS}

The pathophysiological basis of the association between ACS and SARS-CoV-2 stems from the ability of the virus to infect blood vessels in vitro and endothelial cells [23]. It has been demonstrated that SARS-CoV-2 gains entry into cells via ACE2, which is expressed in different organs including lung and heart [3]. Specifically in the heart, ACE2 was shown to be expressed by coronary vascular endothelium, smooth muscle cells, cardiac fibroblasts, epicardial adipocytes, and cardiac myocytes [38]. These associations could explain the increased incidence of multiorgan dysfunction 
and both micro and macro-vascular thrombotic events in COVID-19 patients [34].

The relationship between COVID-19 and ACS is distinctly controversial. Many studies found decreased incidence of ACS hospitalizations during the pandemic as compared to before it [59]. Whether this was due to reduced incidence or other reasons, including fear of patients of contracting COVID-19 from the healthcare facilities and decreased awareness of ACS, remains unclear. Undoubtedly, COVID-19 posed a challenge for proper ACS diagnosis because of its association with cardiac conditions mimicking ACS, such as myo-pericarditis, coronary artery vasospasm, pulmonary embolism, or stress-induced cardiomyopathy. For instance, in 1 case series of 18 patients with COVID-19 and ST segment elevation on ECG, only $67 \%$ of those who underwent angiography had obstructive coronary disease, yet this group had a high mortality rate (72\%) [32]. Furthermore, in a retrospective study of 78 patients, higher numbers of complications were reported in ACS COVID-19 patients, as compared to those without COVID-19, including acute respiratory distress syndrome $(10 \%)$, hemorrhagic stroke (9\%), in-hospital mortality (26\%) and stent thrombosis [60]. Moreover, this study reported avoidance of PCI as a primary treatment, with more than half of the patients receiving fibrinolytic therapy (59\%) rather than the recommended PCI (24\%), which coincides with other studies' conclusions [61].

However, data regarding COVID-19 direct effect on ACS remain conflicting and the association uncertain. For instance, in a recent systematic review of 50,123 patients, the authors concluded no difference emerged in in-hospital mortality and time to obtain medical care in ST-elevation myocardial infarction (STEMI) patients before and during the pandemic. They did report, however, increased door-to balloon-time and declines in STEMI admissions [62]. These studies, despite seemingly with conflicting results, coincide on the significant effect of COVID-19 on ACS diagnosis, prognosis and management; however, the extent of this effect has yet to be determined.

\section{Arrhythmias}

Cardiac rhythm disturbances are among the most common CV complications in the setting of acute COVID-19 [63]. Recent meta-analyses have reported that these events occur in up to $19 \%$ of hospitalized patients with SARS-CoV-2 [64] with a substantially higher incidence in those admitted to ICU versus non-ICU encounters (44\% vs 6.9\%) [65]. However, the real incidence of arrythmias is difficult to establish because of barriers towards the performance of full 12-lead ECG in contagious SARS-CoV-2-infected patients, and thus could be underestimated [63]. Notwithstanding, arrythmias appear to be important to detect because of their major impact on outcome and significant in-hospital mortality risk (RR 7.96 [95\% C.I.s 3.77, 16.81], $p<0.001$; $I^{2}: 71.1 \%, p=0.02$ ) [64]. Different types of arrythmias have been associated with COVID-19 including atrial fibrillation, atrioventricular blocks, polymorphic ventricular tachycardia, and pulseless electric activity, not always correlating with the severity of lung injury [66]. Supraventricular tachycardias (atrial fibrillation/atrial flutter) are among the most commonly described heart rhythm disturbances with an estimated prevalence of $15.8 \%$ (166/1053) as reported by Peltzer et al. [67]. Of note, in this study, 101 out of 166 $(60.8 \%)$ patients had no prior history of atrial fibrillation or atrial flutter.

A number of mechanisms of cardiac dysrhythmias' in COVID-19 have been postulated. As mentioned above, SARS-CoV-2 direct damage to cardiomyocytes leading to viral myocarditis could predispose to ventricular arrhythmias [3]. In addition, COVID-19 patients, especially if hospitalized, develop electrolyte disturbances or systemic inflammation [68], which may trigger arrhythmias. Moreover, several drugs administered in the course of the infection may exert arrhythmogenic effects, including azithromycin and hydroxychloroquine [69]. These drugs, inducing QT prolongation, can increase the risk of arrhythmias such as torsades de point and ventricular tachycardia. The risk of QT prolongation drastically rises when these drugs are administered in combination regimens. For example, hydroxychloroquine plus azithromycin was found to prolong QT of $>30 \mathrm{~ms}$ in $76 \%$ of cases [70]. In brief, various arrhythmias frequently occur in COVID-19, correlate with disease severity and worsen prognosis, suggesting close ECG monitoring is warranted in all cases.

\section{Heart failure}

De novo heart failure (HF) has a major impact on prognosis of patients hospitalized for acute COVID-19. Indeed, Zhou et al. found that, among 191 patients, 44 (23\%) developed HF with a significant difference between survivors and non-survivors (52\% vs $12 \%, p<0.0001)$ [38]. Other studies suggest that HF incidence may be even higher. Bieber et al. observed that left ventricular dysfunction (both systolic and/or diastolic) and systolic right ventricular dysfunction occurred in $56 \%$ of their total cohort (116 pts) and more frequently in patients with increased troponin ( $88.8 \%$ vs. $14.3 \%, p<0.001$ ) [71]. Moreover, this complication occurs regardless of a prior history of $\mathrm{CD}$ [72], suggesting a direct role of SARS-CoV-2 infection in its pathogenesis.

Heart dysfunction presents with different patterns. Echocardiography performed in the acute stage of the disease reveals that the most common abnormalities are right ventricular (RV) dilation (39\%) and left ventricular diastolic dysfunction (16\%) [73]. COVID-19 patients are more prone to develop thromboembolic complications, such as venous 
thrombosis and pulmonary thromboembolism [74], which in turn could underlie RV dysfunction. In addition, alveolar hypoxia in severe cases and acute respiratory distress syndrome (ARDS) in critically ill patients with COVID-19 could worsen RV function by increasing pulmonary vascular resistances and RV afterload [75]. In this context, noninvasive as well as invasive mechanical ventilation may also exert a negative effect [76].

With regards to left ventricular (LV) function, HF with preserved ejection fraction (HFpEF) is a common finding in COVID-19 [73]. This may be due to preexisting subclinical HFpEF or de novo diastolic dysfunction caused by common mechanisms between both diseases like systemic inflammation and hypoxemia [76]. Moreover, HFpEF and COVID19 seem to share a number of cardiometabolic risk factors including older age and obesity, making it more important to investigate, given the increasing prevalence of obesity in Western countries which could translate into increased susceptibility to severe COVID-19, however, the extent of the effect and the interaction between both diseases has yet to be determined [76]. In summary, published evidence suggests de novo HF frequently complicates COVID-19, implies (RV) overload/dilation and LV diastolic dysfunction, and has a major impact on overall prognosis.

\section{Conclusions}

After more than a year of intense investigations, much has been learned on COVID-19 and CD. SARS-CoV-2 could directly infect the heart via binding to ACE-2 expressed by coronary vascular endothelium, vascular smooth muscle cells, cardiac fibroblasts and myocytes, and epicardial adipocytes. However, direct viral effects are yet to be clearly established.

COVID-19-related myocarditis frequently occurs in conjunction with troponin increase and may have an immunemediated rather than a viral-induced pathologic mechanism. Its presentation is highly variable and may range from asymptomatic to refractory cardiac dysfunction, largely paralleling the extent of lung involvement. Hyperinflammatory response and some emotional stress underlie the association of COVID-19 with TTS, whose real incidence remains unclear but whose prognosis appears fair. ACS have not been consistently shown to be associated with COVID19 , although health-care disruption due to pandemic has likely exerted an unfavorable effect on their management and prognosis. Of utmost significance, COVID-19 is frequently complicated by arrhythmias, with inflammation, myocarditis and drugs playing the most important pathophysiologic role. Arrhythmias may substantially impact the clinical course of acute COVID-19 and may represent the final cause of cardiac arrest and death. All mentioned cardiac hits may eventually lead to the development of HF with right heart involvement coupled with LV diastolic dysfunction.

In conclusion, an attentive cardiac assessment is warranted in COVID-19 patients irrespective of their prior clinical history of CD. Work up should include ECG recording and, for those hospitalized, serial troponin measurements and careful assessment of fluid and electrolyte balance, with a low threshold for functional echocardiography assessment. This should be of enough quality to analyze RV function and LV diastole. Major uncertainties remain as to whether specific cardiovascular treatments should be avoided or would be beneficial in COVID-19 patients with cardiac involvement. These will likely be the subject of future investigation.

Acknowledgements Members of the Monaldi Hospital Cardiovascular Infection Study Group: Emanuele Durante-Mangoni MD, PhD, Domenico Iossa PhD, Lorenzo Bertolino MD, Maria Paola Ursi MD, Fabiana D'Amico BSc, Arta Karruli MD, Mohammad Ramadan MD, Roberto Andini MD, Rosa Zampino MD (Internal Medicine); Mariano Bernardo MSc, Giuseppe Ruocco MSc (Microbiology); Giovanni Dialetto MD, Franco Enrico Covino MD, Sabrina Manduca MD (Echocardiography); Alessandro Della Corte MD, PhD, Marisa De Feo MD, $\mathrm{PhD}$ (Cardiac Surgery); Stefano De Vivo MD (Electrophysiology); Maria Luisa De Rimini MD (Nuclear Medicine); Nicola Galdieri MD (Intensive Care Unit).

Author contribution MSR, LB, MT, MTF and EDM worked on concept of the work, data retrieval and interpretation, drafting and critical revision of the manuscript, and approved the final draft.

Funding Open access funding provided by Università degli Studi della Campania Luigi Vanvitelli within the CRUI-CARE Agreement. No specific funding was obtained for this study.

Availability of data and material All data are derived from current literature.

\section{Declarations}

Conflict of interest None of the authors has any conflict of interest relevant to the content of this work. There are no competing interests.

Ethics approval This work did not raise any ethical issue.

Open Access This article is licensed under a Creative Commons Attribution 4.0 International License, which permits use, sharing, adaptation, distribution and reproduction in any medium or format, as long as you give appropriate credit to the original author(s) and the source, provide a link to the Creative Commons licence, and indicate if changes were made. The images or other third party material in this article are included in the article's Creative Commons licence, unless indicated otherwise in a credit line to the material. If material is not included in the article's Creative Commons licence and your intended use is not permitted by statutory regulation or exceeds the permitted use, you will need to obtain permission directly from the copyright holder. To view a copy of this licence, visit http://creativecommons.org/licenses/by/4.0/. 


\section{References}

1. Havers FP, Reed C, Lim T et al (2020) Seroprevalence of antibodies to SARS-CoV-2 in 10 sites in the United States, March 23-May 12, 2020. JAMA Intern Med. https://doi.org/10.1001/jamaintern med.2020.4130

2. Lai CC, Ko WC, Lee PI, Jean SS, Hsueh PR (2020) Extra-respiratory manifestations of COVID-19. Int J Antimicrob Agents 56:106024. https://doi.org/10.1016/j.ijantimicag.2020.106024

3. Nishiga M, Wang DW, Han Y, Lewis DB, Wu JC (2020) COVID19 and cardiovascular disease: from basic mechanisms to clinical perspectives. Nat Rev Cardiol 17:543-558. https://doi.org/10. 1038/s41569-020-0413-9

4. Zhu Z, Lian X, Su X, Wu W, Marraro GA, Zeng Y (2020) From SARS and MERS to COVID-19: a brief summary and comparison of severe acute respiratory infections caused by three highly pathogenic human coronaviruses. Respir Res 21:224. https://doi. org/10.1186/s12931-020-01479-w

5. World Health Organization W. Middle East respiratory syndrome coronavirus (MERS-CoV)—United Arab Emirates. 2021; Available from: https://www.who.int/emergencies/disease-outbreaknews/item/2021-DON314.Accessed 29 Mar 2021

6. Assiri A, Al-Tawfiq JA, Al-Rabeeah AA et al (2013) Epidemiological, demographic, and clinical characteristics of 47 cases of Middle East respiratory syndrome coronavirus disease from Saudi Arabia: a descriptive study. Lancet Infect Dis 13:752-761. https:// doi.org/10.1016/S1473-3099(13)70204-4

7. Chan JW, Ng CK, Chan YH, Mok TY, Lee S, Chu SY, Law WL, Lee MP, Li PC (2003) Short term outcome and risk factors for adverse clinical outcomes in adults with severe acute respiratory syndrome (SARS). Thorax 58:686-689. https://doi.org/10.1136/ thorax.58.8.686

8. Guo T, Fan Y, Chen M et al (2020) Cardiovascular implications of fatal outcomes of patients with Coronavirus disease 2019 (COVID-19). JAMA Cardiology 5:811-818. https://doi.org/10. 1001/jamacardio.2020.1017

9. Shi S, Qin M, Cai Y et al (2020) Characteristics and clinical significance of myocardial injury in patients with severe coronavirus disease 2019. Eur Heart J 41:2070-2079. https://doi.org/10.1093/ eurheartj/ehaa408

10. Univerisity JH. Mortality in the most affected countries. MORTALITY ANALYSES 2021; Available from: https://coronavirus. jhu.edu/data/mortality. Accessed 30 Mar 2021

11. Shi S, Qin M, Shen B et al (2020) Association of cardiac injury with mortality in hospitalized patients with COVID-19 in Wuhan, China. JAMA Cardiol 5:802-810. https://doi.org/10.1001/jamac ardio.2020.0950

12. Figliozzi S, Masci PG, Ahmadi N et al (2020) Predictors of adverse prognosis in COVID-19: a systematic review and metaanalysis. Eur J Clin Invest 50:e13362. https://doi.org/10.1111/eci. 13362

13. Turner AJ, Hiscox JA, Hooper NM (2004) ACE2: from vasopeptidase to SARS virus receptor. Trends Pharmacol Sci 25:291-294. https://doi.org/10.1016/j.tips.2004.04.001

14. Ni W, Yang X, Yang D et al (2020) Role of angiotensin-converting enzyme 2 (ACE2) in COVID-19. Crit Care 24:422. https://doi.org/ 10.1186/s13054-020-03120-0

15. Escher F, Pietsch H, Aleshcheva G et al (2020) Detection of viral SARS-CoV-2 genomes and histopathological changes in endomyocardial biopsies. ESC Heart Fail 7:2440-2447. https://doi. org/10.1002/ehf2.12805

16. Tay MZ, Poh CM, Rénia L, MacAry PA, Ng LFP (2020) The trinity of COVID-19: immunity, inflammation and intervention. Nat Rev Immunol 20:363-374. https://doi.org/10.1038/ s41577-020-0311-8
17. Huang C, Wang Y, Li X et al (2020) Clinical features of patients infected with 2019 novel coronavirus in Wuhan, China. Lancet 395:497-506. https://doi.org/10.1016/S0140-6736(20)30183-5

18. Xu Z, Shi L, Wang Y et al (2020) Pathological findings of COVID-19 associated with acute respiratory distress syndrome. Lancet Respir Med 8:420-422. https://doi.org/10.1016/s22132600(20)30076-X

19. Liao M, Liu Y, Yuan J et al (2020) Single-cell landscape of bronchoalveolar immune cells in patients with COVID-19. Nat Med 26:842-844. https://doi.org/10.1038/s41591-020-0901-9

20. Libby P, Tabas I, Fredman G, Fisher EA (2014) Inflammation and its resolution as determinants of acute coronary syndromes. Circ Res 114:1867-1879. https://doi.org/10.1161/CIRCRESAHA.114. 302699

21. Frydman GH, Tessier SN, Wong KHK, Vanderburg CR, Fox JG, Toner M, Tompkins RG, Irimia D (2020) Megakaryocytes contain extranuclear histones and may be a source of platelet-associated histones during sepsis. Sci Rep 10:4621-4621. https://doi.org/10. 1038/s41598-020-61309-3

22. Panigada M, Bottino N, Tagliabue P, Grasselli G, Novembrino C, Chantarangkul V, Pesenti A, Peyvandi F, Tripodi A (2020) Hypercoagulability of COVID-19 patients in intensive care unit: a report of thromboelastography findings and other parameters of hemostasis. J Thromb Haemost 18:1738-1742. https://doi.org/10. $1111 /$ jth. 14850

23. Varga Z, Flammer AJ, Steiger P et al (2020) Endothelial cell infection and endotheliitis in COVID-19. Lancet 395:1417-1418. https://doi.org/10.1016/S0140-6736(20)30937-5

24. Grasselli G, Zangrillo A, Zanella A et al (2020) Baseline characteristics and outcomes of 1591 patients infected with SARSCoV-2 admitted to ICUs of the Lombardy Region, Italy. JAMA 323:1574-1581. https://doi.org/10.1001/jama.2020.5394

25. Stokes EK, Zambrano LD, Anderson KN, Marder EP, Raz KM, El Burai FS, Tie Y, Fullerton KE (2020) Coronavirus disease 2019 case surveillance-United States, January 22-May 30, 2020. MMWR Morb Mortal Wkly Rep 69:759-765. https://doi.org/10. 15585/mmwr.mm6924e2

26. Guan W-j, Ni Z-y, Hu Y et al (2020) Clinical characteristics of coronavirus disease 2019 in China. N Engl J Med 382:1708-1720. https://doi.org/10.1056/NEJMoa2002032

27. Wang B, Li R, Lu Z, Huang Y (2020) Does comorbidity increase the risk of patients with COVID-19: evidence from meta-analysis. Aging (Albany NY) 12:6049-6057. https://doi.org/10.18632/ aging. 103000

28. Williamson EJ, Walker AJ, Bhaskaran K et al (2020) Factors associated with COVID-19-related death using OpenSAFELY. Nature 584:430-436. https://doi.org/10.1038/s41586-020-2521-4

29. Zhou Y, Chi J, Lv W, Wang Y (2021) Obesity and diabetes as high-risk factors for severe Coronavirus disease 2019 (Covid19). Diabetes Metab Res Rev 37:e3377-e3377. https://doi.org/ 10.1002/dmrr.3377

30. Gao YD, Ding M, Dong X et al (2020) Risk factors for severe and critically ill COVID-19 patients: a review. Allergy. https://doi.org/ 10.1111/all.14657

31. Pietrobon AJ, Teixeira FME, Sato MN (2020) I mmunosenescence and inflammaging: risk factors of severe COVID-19 in older people. Front Immunol 11:579220-579220. https://doi.org/10.3389/ fimmu.2020.579220

32. Bangalore S, Sharma A, Slotwiner A et al (2020) ST-segment elevation in patients with Covid-19-a case series. N Engl J Med 382:2478-2480. https://doi.org/10.1056/NEJMc2009020

33. Giustino G, Croft LB, Oates CP, Rahman K, Lerakis S, Reddy VY, Goldman M (2020) Takotsubo cardiomyopathy in COVID-19. J Am Coll Cardiol 76:628-629. https://doi.org/10.1016/j.jacc.2020. 05.068 
34. Iba T, Connors JM, Levy JH (2020) The coagulopathy, endotheliopathy, and vasculitis of COVID-19. Inflamm Res 69:1181-1189. https://doi.org/10.1007/s00011-020-01401-6

35. Inciardi RM, Lupi L, Zaccone $G$ et al (2020) Cardiac involvement in a patient with Coronavirus disease 2019 (COVID-19). JAMA Cardiol 5:819-824. https://doi.org/10.1001/jamacardio.2020.1096

36. Kim IC, Kim JY, Kim HA, Han S (2020) COVID-19-related myocarditis in a 21-year-old female patient. Eur Heart J 41:1859. https://doi.org/10.1093/eurheartj/ehaa288

37. Fried JA, Ramasubbu K, Bhatt R et al (2020) The variety of cardiovascular presentations of COVID-19. Circulation 141:1930 1936. https://doi.org/10.1161/CIRCULATIONAHA.120.047164

38. Zhou F, Yu T, Du R et al (2020) Clinical course and risk factors for mortality of adult inpatients with COVID-19 in Wuhan, China: a retrospective cohort study. Lancet 395:1054-1062. https://doi. org/10.1016/s0140-6736(20)30566-3

39. Bavishi C, Bonow RO, Trivedi V, Abbott JD, Messerli FH, Bhatt DL (2020) Special article-Acute myocardial injury in patients hospitalized with COVID-19 infection: a review. Prog Cardiovasc Dis 63:682-689. https://doi.org/10.1016/j.pcad.2020.05. 013

40. Caforio ALP, Pankuweit S, Arbustini E et al (2013) Current state of knowledge on aetiology, diagnosis, management, and therapy of myocarditis: a position statement of the European Society of Cardiology Working Group on Myocardial and Pericardial Diseases. Eur Heart J 34:2636-2648. https://doi.org/10.1093/eurhe artj/eht 210

41. Castiello T, Georgiopoulos G, Finocchiaro G, Claudia M, Gianatti A, Delialis D, Aimo A, Prasad S (2021) COVID-19 and myocarditis: a systematic review and overview of current challenges. Heart Fail Rev. https://doi.org/10.1007/s10741-021-10087-9

42. Ho JS, Sia CH, Chan MY, Lin W, Wong RC (2020) Coronavirus-induced myocarditis: a meta-summary of cases. Heart Lung 49:681-685. https://doi.org/10.1016/j.hrtlng.2020.08.013

43. Zorzi A, Perazzolo Marra M, Rigato I et al (2016) Nonischemic left ventricular scar as a substrate of life-threatening ventricular arrhythmias and sudden cardiac death in competitive athletes. Circ Arrhythm Electrophysiol 9:e004229. https://doi.org/10.1161/circep. 116.004229

44. Escher F, Westermann D, Gaub R, Pronk J, Bock T, Al-Saadi N, Kühl U, Schultheiss HP, Tschöpe C (2011) Development of diastolic heart failure in a 6-year follow-up study in patients after acute myocarditis. Heart 97:709-714. https://doi.org/10.1136/hrt. 2010.199489

45. Sawalha K, Abozenah M, Kadado AJ, Battisha A, Al-Akchar M, Salerno C, Hernandez-Montfort J, Islam AM (2021) Systematic review of COVID-19 related myocarditis: insights on management and outcome. Cardiovasc Revasc Med 23:107-113. https://doi. org/10.1016/j.carrev.2020.08.028

46. Becker RC (2020) Anticipating the long-term cardiovascular effects of COVID-19. J Thromb Thrombolysis 50:512-524. https://doi.org/10.1007/s11239-020-02266-6

47. Fayol A, Livrozet M, Boutouyrie P et al (2021) Cardiac performance in patients hospitalized with COVID-19: a 6 month followup study. ESC Heart Failure. https://doi.org/10.1002/ehf2.13315

48. Maron BJ, Udelson JE, Bonow RO et al (2015) Eligibility and disqualification recommendations for competitive athletes with cardiovascular abnormalities: task force 3: hypertrophic cardiomyopathy, arrhythmogenic right ventricular cardiomyopathy and other cardiomyopathies, and myocarditis: a scientific statement from the American heart association and American college of cardiology. Circulation 132:e273-e280. https://doi.org/10.1161/ CIR.0000000000000239

49. Phelan D, Kim JH, Chung EH (2020) A game plan for the resumption of sport and exercise after Coronavirus disease 2019
(COVID-19) infection. JAMA Cardiol. https://doi.org/10.1001/ jamacardio.2020.2136

50. Singh S, Desai R, Gandhi Z et al (2020) Takotsubo syndrome in patients with COVID-19: a systematic review of published cases. SN Compr Clin Med. https://doi.org/10.1007/ s42399-020-00557-w

51. Lyon AR, Citro R, Schneider B, Morel O, Ghadri JR, Templin C, Omerovic E (2021) Pathophysiology of Takotsubo syndrome: JACC State-of-the-Art review. J Am Coll Cardiol 77:902-921. https://doi.org/10.1016/j.jacc.2020.10.060

52. Roca E, Lombardi C, Campana M, Vivaldi O, Bigni B, Bertozzi B, Passalacqua G (2020) Takotsubo syndrome associated with COVID-19. Eur J Case Rep Intern Med 7:001665. https://doi.org/ 10.12890/2020_001665

53. Park JH, Moon JY, Sohn KM, Kim YS (2020) Two fatal cases of stress-induced cardiomyopathy in COVID-19 patients. J Cardiovasc Imaging 28:300-303. https://doi.org/10.4250/jcvi.2020.0125

54. Nguyen D, Nguyen T, De Bels D, Castro Rodriguez J (2020) A case of Takotsubo cardiomyopathy with COVID 19. Eur Heart J Cardiovasc Imaging 21:1052. https://doi.org/10.1093/ehjci/jeaa1 52

55. Meyer P, Degrauwe S, Van Delden C, Ghadri JR, Templin C (2020) Typical takotsubo syndrome triggered by SARS-CoV-2 infection. Eur Heart J 41:1860. https://doi.org/10.1093/eurheartj/ ehaa306

56. Minhas AS, Scheel P, Garibaldi B, Liu G, Horton M, Jennings M, Jones SR, Michos ED, Hays AG (2020) Takotsubo syndrome in the setting of COVID-19. JACC Case Rep 2:1321-1325. https:// doi.org/10.1016/j.jaccas.2020.04.023

57. Tsao CW, Strom JB, Chang JD, Manning WJ (2020) COVID19-Associated stress (Takotsubo) cardiomyopathy. Circ Cardiovasc Imaging 13:e011222. https://doi.org/10.1161/CIRCIMAGING.120.011222

58. Park CL, Russell BS, Fendrich M, Finkelstein-Fox L, Hutchison M, Becker J (2020) Americans' COVID-19 stress, coping, and adherence to CDC guidelines. J Gen Intern Med 35:2296-2303. https://doi.org/10.1007/s11606-020-05898-9

59. Solomon MD, McNulty EJ, Rana JS, Leong TK, Lee C, Sung SH, Ambrosy AP, Sidney S, Go AS (2020) The Covid-19 pandemic and the incidence of acute myocardial infarction. N Engl J Med 383:691-693. https://doi.org/10.1056/NEJMc2015630

60. Hamadeh A, Aldujeli A, Briedis K et al (2020) Characteristics and outcomes in patients presenting with COVID-19 and ST-segment elevation myocardial infarction. Am J Cardiol 131:1-6. https:// doi.org/10.1016/j.amjcard.2020.06.063

61. Daoulah A, Hersi AS, Al-Faifi SM et al (2021) STEMI and COVID-19 pandemic in Saudi Arabia. Curr Probl Cardiol 46:100656. https://doi.org/10.1016/j.cpcardiol.2020.100656

62. Rattka M, Dreyhaupt J, Winsauer C, Stuhler L, Baumhardt M, Thiessen K, Rottbauer W, Imhof A (2020) Effect of the COVID19 pandemic on mortality of patients with STEMI: a systematic review and meta-analysis. Heart. https://doi.org/10.1136/heart jnl-2020-318360

63. Malaty M, Kayes T, Amarasekera AT, Kodsi M, MacIntyre CR, Tan TC (2021) Incidence and treatment of arrhythmias secondary to coronavirus infection in humans: a systematic review. Eur J Clin Invest 51:e13428. https://doi.org/10.1111/eci.13428

64. Pranata R, Huang I, Raharjo SB (2020) Incidence and impact of cardiac arrhythmias in coronavirus disease 2019 (COVID-19): a systematic review and meta-analysis. Indian Pacing Electrophysiol J 20:193-198. https://doi.org/10.1016/j.ipej.2020.08.001

65. Wang D, Hu B, Hu C et al (2020) Clinical characteristics of 138 hospitalized patients with 2019 novel coronavirus-infected pneumonia in Wuhan, China. JAMA 323:1061-1069. https://doi.org/ 10.1001/jama.2020.1585 
66. Kochav SM, Coromilas E, Nalbandian A et al (2020) Cardiac arrhythmias in COVID-19 infection. Circ Arrhythm Electrophysiol 13:e008719. https://doi.org/10.1161/circep.120.008719

67. Peltzer B, Manocha KK, Ying X et al (2020) Arrhythmic complications of patients hospitalized with COVID-19: incidence, risk factors, and outcomes. Circ Arrhythm Electrophysiol 13:e009121. https://doi.org/10.1161/circep.120.009121

68. Lazzerini PE, Capecchi PL, Laghi-Pasini F (2017) Systemic inflammation and arrhythmic risk: lessons from rheumatoid arthritis. Eur Heart J 38:1717-1727. https://doi.org/10.1093/eurheartj/ ehw208

69. Ete T, Fanai V, Bamon A, Khan S, Kumar U, Kumar A, Bhatia D, Mishra A (2020) Disease, drugs and dilemma: a review of cardiovascular implications of novel COVID-19. Clin Infect Immun 5:25-30. https://doi.org/10.14740/cii109

70. Voisin O, Lorc'h EL, Mahé A, Azria P, Borie MF, Hubert S, Ménage E, Guillerm JC, Mourad JJ (2020) Acute QT interval modifications during hydroxychloroquine-azithromycin treatment in the context of COVID-19 infection. Mayo Clin Proc 95:16961700. https://doi.org/10.1016/j.mayocp.2020.05.005

71. Bieber S, Kraechan A, Hellmuth JC et al (2021) Left and right ventricular dysfunction in patients with COVID-19-associated myocardial injury. Infection. https://doi.org/10.1007/ s15010-020-01572-8

72. Chen T, Wu D, Chen H et al (2020) Clinical characteristics of 113 deceased patients with coronavirus disease 2019: retrospective study. BMJ 368:m1091. https://doi.org/10.1136/bmj.m1091
73. Szekely Y, Lichter Y, Taieb P et al (2020) Spectrum of cardiac manifestations in COVID-19: a systematic echocardiographic study. Circulation 142:342-353. https://doi.org/10.1161/circu lationaha.120.047971

74. Bikdeli B, Madhavan MV, Jimenez D et al (2020) COVID-19 and thrombotic or thromboembolic disease: implications for prevention, antithrombotic therapy, and follow-Up: JACC state-of-theart review. J Am Coll Cardiol 75:2950-2973. https://doi.org/10. 1016/j.jacc.2020.04.031

75. Creel-Bulos C, Hockstein M, Amin N, Melhem S, Truong A, Sharifpour M (2020) Acute cor pulmonale in critically Ill patients with Covid-19. N Engl J Med 382:e70. https://doi.org/10.1056/ NEJMc2010459

76. Freaney PM, Shah SJ, Khan SS (2020) COVID-19 and heart failure with preserved ejection fraction. JAMA 324:1499-1500. https://doi.org/10.1001/jama.2020.17445

Publisher's Note Springer Nature remains neutral with regard to jurisdictional claims in published maps and institutional affiliations. 